\title{
MOVIMENTOS SOCIAIS URBANOS E A CONSOLIDAÇÃO DA DEMOCRACIA
}

\author{
Luana Nascimento Perin \\ Universidade Regional do Noroeste do Estado do Rio Grande do Sul - Unijuí - Brasil \\ Eloísa Nair de Andrade Argerich \\ Universidade Regional do Noroeste do Estado do Rio Grande do Sul - Unijuí - Brasil
}

\begin{abstract}
Resumo
O presente artigo faz uma abordagem sobre a questão da democracia e a liberdade de expressão no Brasil, ao mesmo tempo em que analisa os movimentos sociais, com enfoque para os movimentos urbanos, que vêm tomando força na atual conjuntura social devido à propagação das redes sociais, cada vez mais presentes nas relações da sociedade. $\mathrm{O}$ advento da Internet, nesse viés, muito contribui para que as informações se propaguem de maneira imediata em todo globo. Contudo, deve-se atentar que nem sempre as informações prestadas são seguras e, além disso, podem ter sua interpretação distorcida pelos leitores que, ao mesmo tempo, tornam-se propagadores da distorção informacional. Por fim, o estudo menciona as principais lutas pela redemocratização do país e a sua importância para a consolidação da democracia.
\end{abstract}

Palavras-chave: Democracia. Liberdade de expressão. Movimentos sociais urbanos. Meios de comunicação.

\section{Introdução}

O presente artigo tem como objetivo propiciar aos leitores o entendimento sobre a democracia e a liberdade de expressão no Brasil e, principalmente, sobre a democracia participativa, a qual desencadeia os movimentos sociais, tanto urbanos quanto rurais. Entretanto, serão aprofundados somente os movimentos sociais urbanos, pois estes ganharam maior força no atual cenário devido aos novos meios de comunicação, tais como a Internet, que deu margem à criação do Facebook, do Twitter, e demais redes sociais.

O estudo não destaca apenas os pontos favoráveis dessa nova era, mas também enfatiza os cuidados necessários com o sistema informacional na Internet, uma vez que as informações 
passam por diversos leitores e são transmitidas, muitas vezes, de maneira equivocada e contraditória aos reais acontecimentos.

Na maioria das vezes os movimentos sociais contemporâneos são organizados nas redes sociais e, por esse motivo, é preciso ficar atento à realidade pois para ser entendido como "movimento social" ele deve possuir um objetivo com uma causa comum, e reivindicar, por exemplo, reforma agrária, casas populares, pavimentação asfáltica, iluminação, etc. Um dos maiores exemplos a serem citados foi o caso das "Diretas Já", movimento realizado em 1983/1984, e que possuía como objetivo a restauração da democracia no Brasil por meio das eleições presidenciais. Com o Golpe Militar de 1964 a Presidência da República passou a ser comandada por militares, e desde então não houve novas eleições presidenciais.

Este artigo pretende verificar a importância dos movimentos sociais urbanos para a consolidação da democracia, cujo evento reuniu milhares de pessoas que reivindicavam um mesmo fim, sempre com o objetivo de trazer benefícios para todos os cidadãos brasileiros.

\section{Democracia e movimentos sociais urbanos}

Para melhor entendimento acerca dessa temática faz-se necessária uma abordagem sobre os aspectos que sustentam a democracia para, posteriormente, contextualizar os movimentos sociais urbanos. É fundamental compreender a origem e o conceito dos movimentos sociais, suas características e fundamentos, haja vista que as lutas pela redemocratização do país são originárias de movimentos sociais, divulgados pelos meios de comunicação em redes ou por grupos sociais, pelos excluídos ou por aqueles que têm suas demandas não atendidas pelo governo.

Os movimentos sociais, segundo Gohn (2013, p. 40), “constituem-se como um dos sujeitos sociopolíticos presentes no associativismo no Brasil, porque eles foram, e ainda são as bases de muitas ações coletivas no país a partir de 1970." Tais movimentos sociais transitam pelos espaços não consolidados pelo poder político, que não consegue efetivar o atendimento das demandas dos atores sociais na luta por seus pleitos, e se encontram desejosos de expressar sua desconformidade com a ação política e/ou social.

Estes atores sociais surgiram na sociedade civil brasileira após os anos 1970, sem a autorização do Estado e, num primeiro momento, contra o próprio Estado. Constituíram, assim, uma participação à revelia dos interesses estatais, e se consolidaram como um novo espaço de participação democrática e das relações sociopolíticas e sociais.

Barbarói, Santa Cruz do Sul, Edição Especial n.44, p.<87-105>, jul./dez. 2015 
Sobre esse tema Gohn (2011, p. 303) assevera que:

[...] os novos atores sociais que emergiram na sociedade civil brasileira, após 1970, à revelia do Estado, e contra ele num primeiro momento, configuraram novos espaços e formatos de participação e de relações públicas. Estes novos espaços foram construídos basicamente pelos movimentos sociais, populares ou não, nos anos 70-80 (Gohn, 1991); e nos anos 90 por um tipo especial de ONGs que denominamos anteriormente de cidadãs, ou seja, entidades sem fins lucrativos que se orientam para a promoção e para o desenvolvimento de comunidades carentes a partir das relações baseadas em direitos e deveres da cidadania (Gohn, 1994).

Os movimentos sociais podem ser definidos como fenômenos históricos, decorrentes das lutas de classes. Com enfoque nas suas necessidades, os atores sociais buscam com suas ações diretas e discursos, organizados ou não, obter visibilidade e chamar a atenção para as dificuldades que estão condicionadas aos problemas do cotidiano, na busca por melhores condições de vida e de trabalho.

Apesar das variadas teorias sobre os movimentos sociais, Gohn (2004, p. 343, grifo da autora) sustenta que "[...] Nunca haverá uma teoria completamente pronta e acabada sobre eles (movimentos sociais). Os movimentos são fluídos, fragmentados, perpassados por outros processos sociais."

Paulo Silvino Ribeiro ([s.d.], [s.p.]) conceitua os movimentos sociais como a ação coletiva de um grupo organizado "[...] que objetiva alcançar mudanças sociais por meio do embate político, conforme seus valores e ideologias dentro de uma determinada sociedade e dentro de contextos específicos, permeados por tensões sociais."

É possível considerar, então, que os movimentos sociais lutam por melhorias das condições de vida e de trabalho do cidadão, mas, principalmente, buscam a realização de seus anseios, a construção de uma identidade que visa, também, à transformação da sociedade.

A abordagem deste estudo pretende considerar apenas a história dos movimentos sociais urbanos dos últimos 20 anos, o que significa que do universo dos estudos sobre os movimentos a preocupação está em mapear apenas uma faceta dessas mobilizações.

Ao demarcar as diferenças entre os movimentos sociais, a fim de lhes conferir identidade própria, destaca-se que "O repertório de lutas construídas por eles demarcam interesses, identidades, subjetividades e projetos de grupos sociais que não só mobilizam as pessoas, mas mobilizam ideias e valores que contribuem para impulsionar mudanças sociais." (GOHN, 2013, p. 40-41).

Cumpre registrar que no final dos anos 70, segundo Gohn (2011, p. 281): 
[...] no Brasil, quando se falava em novos movimentos sociais, em encontros, seminários e colóquios acadêmicos, tinha-se bem claro de que fenômeno se estava tratando. Era sobre os movimentos sociais populares urbanos, particularmente aqueles que se vinculavam às práticas da Igreja Católica, na ala articulada à Teologia da Libertação. A denominação buscava contrapor os novos movimentos sociais aos ditos já velhos, expressos no modelo clássico das sociedades amigos de bairros ou associações de moradores. O que estava no cerne da diferenciação eram práticas sociais e um estilo de organizar a comunidade local de maneira totalmente distinta.

Embora seja um equívoco, a relação dos movimentos sociais urbanos com o Estado era vista como uma rebelião ou oposição. Na realidade esses movimentos buscavam mudanças sociais nos projetos políticos, sociais e econômicos apresentados pelo governo.

Analistas e consultores de organizações internacionais consideram os movimentos sociais como elementos e fontes de inovações e mudanças sociais. Não se pode olvidar, contudo, que estes movimentos "[...] detêm um saber decorrente de suas práticas cotidianas, passíveis de serem apropriadas e transformadas em força produtiva." (GOHN, 2013, p. 41).

Os movimentos sociais populares urbanos sempre ocuparam um papel de destaque na sociedade. Nesse sentido, Gohn (2011, p. 282) assevera que " [...] os movimentos sociais populares urbanos tinham papel de destaque. Eles eram vistos como fontes de poder social. A relação dos movimentos com o Estado era vista em termos de antagonismo e oposição".

O papel exercido pela Igreja na estruturação dos movimentos sociais urbanos consistia, principalmente, em ser formadora de opinião, pois "a relação da Igreja era usualmente tratada apenas em termos de apoio ou de matriz formadora/ constituidora das novas forças sociais" (SADER apud GOHN, 2011, p. 283), o que se modificou a partir dos anos 80.

Progressivamente, os movimentos sociais passaram a ter outro referencial e a serem fortemente influenciados pela política estatal. Destaca-se que a história e a sociedade não mostram que é pela articulação dos grupos que se pode perceber as mudanças no cenário sociopolítico, econômico e cultural.

Com efeito, é notável o que Gohn (2011, p. 283) apresenta sobre essas mudanças ao observar que:

As mudanças na conjuntura política no início dos anos 80 vieram a alterar o cenário. No campo popular começou-se a indagar e a questionar o caráter novo dos movimentos populares. No campo das práticas não exclusivamente populares, iniciouse o interesse, por parte dos pesquisadores, por outros tipos de movimentos sociais, tais como o das mulheres, os ecológicos, os dos negros, índios, etc. Foram movimentos que ganharam expressão naquela década, embora fossem lutas já antigas que ressurgiram no Brasil no final dos anos 70. Em alguns casos estiveram articulados à luta popular, como no caso das creches e de algumas alas do movimento feminista. 
As mudanças na conjuntura política e social brasileira e as políticas participativas possibilitam a compreensão de que os movimentos sociais urbanos no Brasil sempre estiveram presentes e atuantes, mas ganharam força neste período, quando uma grande parcela de desempregados do setor produtivo privado saíram às ruas para reivindicar que a agenda pública e governamental contemplasse políticas públicas de desenvolvimento. Também contribuíram para o avanço quantitativo das mobilizações da década de 80 o surgimento de grandes centrais sindicais e o aparecimento de entidades qualificadas como movimentos sociais, os quais realizam articulações para implementar seus objetivos.

O Estado nem sempre foi adversário dos movimentos sociais, mas seu principal interlocutor, notadamente quando, nos anos 90, ocorreu "o aprofundamento do processo de transição democrática, com a ascensão de líderes da oposição, de vários matizes, a cargos no parlamento e na administração de postos governamentais [...]" (GOHN, 2011, p. 288), enfatizando a cidadania e a exclusão social como categorias básicas para a sustentação dos movimentos sociais.

Os elementos básicos que sustentaram os movimentos sociais urbanos na década de 90 foram direcionados às ações que envolvem a cidadania coletiva e a exclusão social. Desta forma, é imprescindível verificar a análise efetuada por Gohn (2011, p. 288) sobre o tema, ao observar que no plano das análises, os anos 90 enfatizarão duas categorias básicas: a cidadania coletiva e a exclusão social. A primeira, já presente na década anterior, apresentará como novidade pensar o exercício da cidadania em termos coletivos, de grupos e instituições que se legitimaram juridicamente a partir de 88 , e que têm de desenvolver um novo aprendizado, pois não se trata apenas de reivindicar, pressionar ou demandar.

Ao dar ênfase às categorias dos excluídos da cidadania coletiva, cientistas políticos, dentre eles Touraine, Marshall e Dahrendorf, afirmam que a qualidade do conflito existente nos movimentos sociais se modificou, não ocorrendo mais em torno das diferenças e desigualdade sociais. Elas passam, sim, a se restringir à participação cívica nas decisões políticas, econômicas ou sociais, tomada pelos governantes, quando envolvem direitos e obrigações e a precariedade de serviços essenciais prestados à população (apud GOHN, 2011, p. 289).

Neste cenário, Dahrendorf (apud GOHN, 2011, p. 289) destaca que: 
privilégios continuam a ser a questão fundamental, e os "cidadãos" meramente ganharam uma nova posição, mais vantajosa, na luta por maiores chances na vida.

Diante das lutas realizadas pelos movimentos sociais urbanos visando à construção de uma sociedade mais justa e solidária é inegável que o Estado passa a ser o elemento responsável pela coesão social. Segundo Castells (apud GOHN, 2011, p. 295), "Ele tem a capacidade de regular as relações políticas de classe, desempenhando um papel de árbitro [...]”, o que confirma que os movimentos sociais organizam-se com a finalidade de lutar pelos seus ideais e exigir o cumprimento das políticas governamentais relativas aos direitos fundamentais.

Os movimentos sociais apresentam características gerais e fundamentos que variam de tempos em tempos, como se observou na análise dos anos 70 a 90 . Ademais, apresentam uma trajetória que ultrapassa as questões sociais e envolve questões políticas e econômicas.

É interessante observar que a trajetória dos movimentos sociais no Brasil nos últimos 20 anos tem como paradigma as teorias não só norte-americana e europeia, mas também latinoamericana. Concentra-se, principalmente, nos movimentos sociais libertários ou emancipatórios, nas lutas populares, nas lutas pela terra, dando atenção às possibilidades de conscientização, mobilização e organização de grupos e movimentos.

No entendimento de Gohn (2011, p. 14) "[...] o paradigma norte-americano possui, em suas diferentes versões, explicações centradas mais nas estruturas das organizações dos chamados sistemas sociopolítico e econômico[...]" e, analisa a ação coletiva, os comportamentos organizacionais e integração social, diferentemente do paradigma europeu.

Não resta dúvida de que na Europa os movimentos sociais apresentavam como paradigma uma abordagem teórica bem diferenciada, e que a abordagem marxista e a dos Novos Movimentos Sociais são consideradas como um espelho para explicar a identidade dos atores sociais.

Sobre as teorias evolucionistas Gohn (2011, p. 14-15) ressalta que "A marxista centrase no estudo dos processos históricos globais, nas contradições existentes e nas lutas entre as diferentes classes sociais."

Destaca-se que o paradigma latino-americano, mais próximo da realidade brasileira, apresenta em seus estudos aspectos fundamentais relacionados aos movimentos sociais libertários ou emancipatórios. Ou seja, movimentos nos quais índios, negros e mulheres lutam para a sua libertação e emancipação social com o intuito de obterem maior espaço na sociedade, consolidando a cidadania participativa. Nota-se que esse paradigma leva à reflexão de que em 
países como Bolívia, Venezuela, Argentina e Paraguai, os novos sujeitos históricos que lutam por uma cidadania coletiva ainda não conseguiram manter uma estratégia de mobilização, organização e conscientização para a obtenção de um mínimo para sobreviver com dignidade (GOHN, 2011, p. 15).

É fundamental adentrar no paradigma dos movimentos sociais no Brasil em virtude da evolução que esses têm apresentado nos últimos 20 anos, e as consequências que têm acarretado no cenário da organização popular em geral.

O que se observa com os movimentos sociais urbanos no Brasil é que esses têm se transformado em um forte fenômeno sociopolítico, pois nunca se viu na história brasileira tantas manifestações coletivas com cidadãos de todas as classes sociais engajados na luta pela transformação social em direção a uma sociedade mais justa e livre. Grupos sociais se unem não para reivindicar direitos, mas para demonstrar sua inconformidade com a corrupção e com o desvio de verbas públicas.

Como ponto decisivo para essa transformação pode-se citar o engajamento de trabalhadores informais, formais, intelectuais, professores, caminhoneiros, comerciários, agricultores, indígenas, etc., em movimentos sociais urbanos ou rurais. Destaca-se, também, a intermediação dos meios de comunicação, considerando principalmente as redes sociais, que em poucos minutos conseguem articular milhares de pessoas em torno de uma causa comum, promovendo uma mobilização veloz e ilimitada.

É inevitável que, na atualidade, os meios de comunicação de massa têm se apresentado como um dos instrumentos mais eficazes para mobilizar pessoas e articular movimentos. $\mathrm{Na}$ visão de Teresa Costa Alves (2013, p. 124), "O século XX caracterizou-se por uma transformação acelerada do paradigma da comunicação, que deixou de evoluir ao ritmo do desenvolvimento humano, biológico, para se aproximar do ritmo dos acontecimentos e sua mediatização."

Ademais, o desenvolvimento de uma sociedade em rede e informacional tem provocado profundas transformações nas comunicações e na troca de informações, acelerando o processo de divulgação, bem como de chamamento aos movimentos sociais para agirem em favor de uma causa comum.

Se, por um lado, é possível afirmar que a liberdade de expressão, garantida pela democracia na Constituição Federal, tem se mostrado transparente e global, tanto que proporciona aos indivíduos o compartilhamento de ideias e conhecimentos, por outro lado a relação dos movimentos sociais urbanos com as redes sociais não tem sido isenta de 
polemização, principalmente ao se observar que o poder institucionalizado se lhes opõe com a força pública (policial).

Observa-se, assim, que "Neste contexto a mídia possui um papel relevante como fonte de interpretação da realidade, modificando e expandindo áreas de experiência individual, intervindo na formação da opinião pública e contribuindo para a definiçãa de identidades individuais e coletivas.” (DELLA PORTA apud PEREIRA, 2011, p. 3).

Destaca Pereira (2011, p. 3) que os meios de comunicação de massa fazem parte do dia a dia do brasileiro, e constituem-se em formadores de opinião. Contribuem, assim, como elementos fundamentais na "disputa pela definição de identidades individuais e coletivas, que perpassam tanto a esfera privada quanto pública. Isto porque a esfera privada tornou-se também um espaço de disputa e mobilização de conflitos", traduzindo os anseios da sociedade civil e possibilitando ao cidadão a sua participação democrática na vida política do Estado brasileiro.

Na verdade, a mídia exerce um papel de destaque na era informacional e contribui para a intermediação das relações sociais entre grupos distintos, bem como para a organização de interesses, mesmo quando se percebe uma crise no sistema representativo e nas organizações governamentais e não governamentais.

É nessa questão que trabalham Valéria Ribas do Nascimento e Márcio Schorn Rodrigues (2014, p. 163) quando ressaltam que "a sociedade informacional é fruto, portanto, da referida inteligência coletiva, que proporciona ao indivíduo a reflexão e o compartilhamento de seus conhecimentos com os seus semelhantes [...]," e se utilizam da Internet para gerar seus conteúdos mediante a interatividade como website.

O desenvolvimento dessa sociedade ocasiona um novo espaço para a comunicação, de forma que ela se torna cada vez mais transparente e universalizada, redefinindo a atuação das instituições públicas, aumentando cada vez mais a sua responsabilidade social. Isso engendra rapidez inédita em campos de ação como a Internet, modificando sobremaneira a atuação e o poder de alcance das mídias tradicionais (LEVY, 2011, p. 55).

Nesse sentido, cumpre destacar que influenciados pela sociedade em rede as pessoas têm modificado o seu modo de pensar, agir e sentir, difundindo, assim, outros meios de expressão e manifestação social, cultural, política, entre outras. Cita-se, por exemplo, a Internet, que tem sido usada de forma muito acentuada e o "[...] uso cada vez mais desenfreado das tecnologias de informação, entendidas como todas as atividades e soluções providas por recursos de computação que visam permitir o seu armazenamento, acesso e o utilização", as 
quais provocam uma revolução nas relações sociais (CASTELLS apud NASCIMENTO; RODRIGUES, 2014, p. 160).

Sabe-se que, na atualidade, "A internet tem sido o grande meio/veículo articulador de ações coletivas e movimentos sociais. Ela possibilitou a criação de redes virtuais que viabilizam conexões de grupos que nunca se encontraram fisicamente de fato." (GOHN, 2013, p. 150). Reconhece-se, portanto, que é por meio da Internet que os eventos são organizados e divulgados e se consegue mobilizar milhares de seguidores.

É importante referir que os mecanismos de comunicação entre os sujeitos na era informacional não se reduzem apenas à imprensa, mas vão do Jornal à Internet/Facebook, sem desmerecer os demais sites de divulgação e informação, como o Twitter, Blog, etc. Dessa forma, o mundo contemporâneo se caracteriza cada vez mais com a intensa participação de todos e em tempos recordes.

Nesse diapasão asseveram Nascimento e Rodrigues (2014, p. 169) que:

\begin{abstract}
As novas tecnologias da informação, propulsoras da sociedade em rede, constituem o fio condutor para que os meios de comunicação se aprimorem e consigam atender às demandas sociais. Ocorre que, na mesma medida em que cresce o número de usuários e de informações lançadas na Internet, por exemplo, aparecem os conflitos gerados por esse manancial de dados que, em última análise, poder servir de instrumento de invasão na privacidade das pessoas.
\end{abstract}

A utilização da Internet ao longo dos anos vem crescendo assustadoramente e os meios de comunicação impressos, a exemplo de jornais e revistas, considerados tradicionais, embora ainda persistam, estão perdendo espaço para os meios virtuais, como Twitter, Blogs, website e Facebook.

Para melhor compreensão do assunto abordam-se neste estudo apenas aspectos relativos ao Facebook, que é considerado um dos “[...] meios das novas tecnologias de informação que possibilitam não apenas a conexão e estruturação das ações, mas têm sido grandes divulgadores das informações e alimentadores das ações e reações em cadeia" (GOHN, 2013, p. 150). Em tempos recordes, eles têm mobilizado milhões de seguidores pelo mundo todo.

A Internet surge como um mecanismo apto a reviver e a revigorar a cidadania que habita nos cidadãos, na vontade de melhorar a qualidade de suas vidas, organizar as comunidades locais e facilitar a troca de informações. Desse modo, os indivíduos, conectados em rede, podem discutir e apresentar aos governantes as soluções para problemas cotidianamente vividos e esquecidos pelos parlamentares que, em muitos momentos, tratam apenas de interesses e vantagens particulares (OLIVEIRA; RODEGHERI, [s.d.], p. 2).

Barbarói, Santa Cruz do Sul, Edição Especial n.44, p.<87-105>, jul./dez. 2015 
A fim de alterar a lógica de comunicação entre as pessoas, a Internet as aproximou e possibilitou discussões e debates dos mais variados temas, principalmente em relação à cidadania e democracia, e não apenas com relação aos direitos e garantias fundamentais.

Pode-se afirmar, inclusive, que as informações que circulam de forma livre nas redes sociais revolucionaram a liberdade de expressão e de manifestação, alicerces da democracia, principalmente se for considerada a dimensão de igualdade dos meios de comunicação. Isso comprova que a conexão em rede facilita a ação e a interação entre as pessoas, bem como a participação cidadã no espaço público.

Ao longo dos anos os meios de comunicação têm contribuído para alterar as formas de expressão da opinião pública, haja vista que as novas tecnologias são grandes facilitadores dos processos de distribuição de informação em prol de uma democracia mais participativa.

Necessário explicitar, portanto, a importância dos meios de comunicação, partindo-se da ideia de que existe liberdade de expressão quando há a publicação de notícias, informações e entretenimento que vão desde os jornais até o Facebook. Não se pode deixar de mencionar ainda que "os fóruns de discussão online utilizadas pelos membros dos movimentos sociais para comunicarem entre si propiciam a discussão sobre os mais variados temas sociais." (ALVES, 2013, p. 3).

Ao observar essas formas de manifestação e informação é importante analisar a função que o jornal exerce na atualidade, já que ele concorre com o meio virtual que tem custo zero, enquanto o impresso exige um pagamento muitas vezes superior àquilo que a pessoa pode dispor.

Nesse contexto, o Facebook também é uma empresa e se faz valer da publicidade para cobrir os custos que, de certa forma, estão embutidos na publicidade/markentig e nos patrocinadores. Ao usar as informações do Facebook, tanto as enviadas quanto as recebidas, o cidadão faz uso das redes de telecomunicações, realizando via privada ou pública, o pagamento de mensalidades contratadas com operadoras de serviços, tais como a Oi, Net, Vivo, Claro, aparelhos utilizados para recebimento do sinal, outros equipamentos, etc.

Mesmo que os meios virtuais sejam utilizados por mais de 89.000 milhões de brasileiros, conforme dados divulgados pelo site Facebook, para Ana Paula de Araújo (2015, [s.p.]):

A função do jornal é basicamente a comunicação. É um dos meios mais rápidos de ficarmos informados a respeito do que acontece no mundo. Dentro do jornal há várias sessões que, por sua vez, abrigam vários tipos de textos. Há algumas características que são comuns a todos estes textos, enquanto há outras que servem para individualizá-los. (grifo da autora). 
Os jornais costumam apresentar um editorial com a relação das matérias veiculadas, que são apresentadas por ordem de relevância e de importância. Ademais, trazem em seu texto, além de notícias sobre fatos ocorridos no mundo e na sociedade, a opinião do editor que, muitas vezes, contraria o que o leitor pensa sobre a matéria. Para tanto, é imperioso que se diga que os veículos de comunicação impressos são tão importantes quanto os meios virtuais (ARAÚJO, 2015).

Observa-se que no momento em que o cidadão, sem pertencer a partidos políticos ou mesmo grupos ativistas, participa de passeatas ou se engaja em movimentos sociais para reivindicar seus direitos, ou apenas para demonstrar sua inconformidade com acontecimentos sociais ou políticos de seu Estado, está exercendo seu direito de cidadania. Por isso, "quanto mais se democratiza um país, mais haverá cidadãos falando de seus problemas em locais não tradicionais da política." (PINTO apud ALVES, 2013, p. 126).

No que diz respeito à comunicação pelos meios virtuais destaca-se o Facebook, pela velocidade instantânea das informações e pelo grande número de acessos. Esta rede social vem inaugurando uma nova forma de liberdade de expressão, pois se assiste diariamente a propagação de registros, os quais se convertem em movimentos sociais.

Assim, Adriana de Araujo Guzzi (2014, p. 228-229) assevera que:

Na mesma medida em que as redes sociais e de compartilhamento de altíssima
densidade - como Orkut, Facebook, Twitter, You Tube, Flickr, entre outras -
propiciaram a abertura para encontros, conversações e comentários por meio de suas
comunidades, além dos sites e blogs pessoais com interatividade, vemos o quanto essa
mídia vem assumindo uma importante função educativa para os jovens. Ainda que a
grande maioria use as redes apenas para se expor e encontrar amigos, são muitos os
que já sabem usá-las para compartilhar interesses comuns e encontrar informações
que vão além do que a escola ou a comunidade dos quais fazem parte podem oferecer.

Em relação ao Facebook não é de espantar que cada vez mais a prática está disseminada, aumentando progressivamente o número de pessoas que o acessam e utilizam este meio virtual para formação de opiniões. "As pesquisas também mostram que cerca de $75 \%$ dos(as) jovens de 16 a 24 anos e $90 \%$ das pessoas com escolaridade acima de superior completo se conectam à Internet." Mas é fundamental que o usuário das redes sociais tenha cautela em relação à utilização desses sites, pois se reconhece que nem todas as fontes de referência são confiáveis (GOHN, 2013, p. 151).

Ressalta Guzzi (2014, p. 230-231) que o Facebook e as redes sociais “[...] tornam-se parte importante das mídias sociais e funcionam como uma autêntica pesquisa de mercado, bem segmentada e a custo baixíssimo."

Barbarói, Santa Cruz do Sul, Edição Especial n.44, p.<87-105>, jul./dez. 2015 
É possível afirmar, inclusive, que hoje as redes sociais, notadamente o Facebook, é o mecanismo mais utilizado na articulação dos movimentos sociais urbanos, e que legitima as ações empreendidas pelos manifestantes, seja na área política, social ou econômica, contrapondo-se, muitas vezes, às necessidades geradas pelo Estado.

A Internet assume um papel fundamental na articulação dos movimentos sociais. No Brasil, o número de acessos ao Facebook cresce de forma assustadora, cujos dados relativos aos usuários da plataforma revelam que

[...] a rede social possui 89 milhões de brasileiros que acessam o site todos os meses. O número corresponde a oito de cada dez internautas, sendo que o número total no país chega a 107,7 milhões. Isso significa que os internautas que acessam o Facebook diariamente totalizam cerca de 59 milhões. Os dados são referentes ao segundo trimestre de 2014. (MEIO \& MENSAGEM, 2015).

Destaca-se que as articulações dos manifestantes em movimentos sociais urbanos ocorrem por meio do Facebook porque é, como já salientado anteriormente, um dos meios mais velozes para mobilizar, articular e engajar pessoas, difundindo ideias que envolvem a luta pela democracia e a liberdade de expressão. "O número de acessos de dispositivos móveis cresceu $55 \%$, o que representa 68 milhões de pessoas. No último ano, a base de pessoas ativas na rede aumentou 105\%, atingindo 41 milhões de pessoas.” (BORJA apud GOHN, 2011, p. 196).

Constata-se que a Internet, ou seja, a utilização do Facebook possibilita ao cidadão participar ativamente da vida política e social do país, não havendo necessidade de gastos com materiais impressos. Basta um chamado pela rede e em poucos minutos milhares de pessoas em todos os cantos do país saem às ruas para protestar pelos seus direitos ou apenas para manifestar sua indignação com a classe política do país.

Oliveira e Rodegheri ([s.d.], p. 2) afirmam que " A grande vantagem decorrente da utilização da Internet é a possibilidade de diversificação das fontes de informação, porque permite a emissão de conteúdo por todo aquele que detém acesso à rede e deseja se expressar $"$.

Por isso, cabe referir que a luta pela redemocratização do país passa necessariamente pelo mapeamento do cenário dos movimentos sociais no Brasil. Essa mobilização de pessoas de todos os Estados, e em torno de um objetivo comum, é fundamental para a compreensão do que está acontecendo atualmente com a mobilização dos movimentos sociais urbanos.

Partindo da análise dos movimentos sociais no Brasil destaca-se que a breve abordagem se refere à Era da Participação, ou seja, de 1978 a 1989, que proporciona a compreensão sobre a temática.

Barbarói, Santa Cruz do Sul, Edição Especial n.44, p.<87-105>, jul./dez. 2015 
Observa-se que os movimentos ocorridos naquela época aconteceram de forma isolada, principalmente na zona rural, e tiveram pouco contato com a zona urbana. É inegável, contudo, que sempre houve um diálogo e debates acadêmicos que visavam acima de tudo compreender a importância da luta pela liberdade de expressão, manifestação e reunião, haja vista a ausência do Estado no cumprimento das demandas sociais.

Gohn (2011, p. 275) enfatiza que "Assim, ao chamar a atenção para o papel do Estado na dinâmica dos movimentos sociais" não se está apenas apontando para a ausência de um dado importante nos estudos, mas também fazendo uma leitura dos fatos segundo uma matriz teórica de abordagem.

Os movimentos sociais urbanos surgiram em vários segmentos da sociedade, mas sua culminância, nos anos 80, se deu em torno das questões urbanas, as quais se acentuaram com o aumento populacional e com o deslocamento de grandes contingentes de pessoas da área rural para as cidades. Sujeitas a várias formas de exclusão social, essas pessoas passaram a se organizar em torno de um objetivo comum, ou seja, à luta pela moradia (GOHN, 2011, p. 276277).

É interessante observar que a realização desta análise se constitui num esboço da trajetória dos movimentos sociais urbanos no Brasil, que sempre atuaram em prol da democratização do país, mais acentuadamente na área dos movimentos sociais urbanos.

A exclusão que se origina do padrão de desenvolvimento econômico adotado pelo país gera a emergência de novos atores, que passam a exigir não apenas mudanças dos rumos da política, mas também o cumprimento das políticas públicas divulgadas nas campanhas políticas e nos planos governamentais dos políticos.

É necessário ressaltar que o padrão de desenvolvimento que gera a exclusão não pode persistir e a sociedade civil precisa se mobilizar para reverter este cenário. Admite Gohn (2011, p. 296) que "[...] o padrão de desenvolvimento que se instaura legitima a exclusão como forma de integração. Passa a ser exclusão integradora, modelo perverso de gestão da crise [...]", recuperando a legitimidade política e criando condições para um novo ciclo de crescimento econômico com a redefinição dos atores sociopolíticos em cena.

A tendência atual é a estruturação de grupos sociais que, com a emergência de novos atores, tais como cidadãos articulados em redes que participam de associações, entidades do Terceiro Setor, Organizações Não Governamentais (ONGs), podem modificar o cenário das relações sociais, trabalhistas e políticas e, assim, exigir um projeto social voltado à inclusão social.

Barbarói, Santa Cruz do Sul, Edição Especial n.44, p.<87-105>, jul./dez. 2015 
A emergência de novos atores ganha força neste século e mostra que podem se mobilizar em torno de temas que dizem respeito a todos, tais como saúde, educação, moradia, enfim, direitos de cidadania.

Vários foram os movimentos nacionais pela redemocratização do país e acesso aos serviços públicos. O marco histórico, porém, foi o movimento nacional pelas “"Diretas Já”,, que reivindicou as eleições diretas para presidente da República, em 1984 (GOHN, 2011).

O papel dos movimentos sociais nesta época são fenômenos que transformaram as relações sociais, sendo agentes do processo de transformação. Entre os movimentos sociais populares urbanos se destaca o "Custo de Vida - Carestia" que, em 1980, lutou contra os altos preços dos alimentos. Além desse destacam-se ainda os movimentos pelos transportes públicos e pela saúde, em 1982, demonstrando que o povo brasileiro já estava atento aos problemas referentes à falta de políticas públicas e sociais do governo para o atendimento das demandas da sociedade.

É imprescindível observar que além dos movimentos nacionais populares urbanos, outros movimentos, tais como sindicais, estudantis, rurais, ecológicos, dentre outros, a partir de 1984 até a presente data, apresentam a emergência de novos atores sociais que lutam por melhoria de condições de vida, bem como pela manutenção da democracia.

Destacam-se, ainda, os movimentos nacionais intitulados "Ética na Política", os quais lutam contra a corrupção (responsável pela articulação que depôs o ex-presidente Collor de Mello, em 1992), bem como os "Caras-Pintadas", movimento estudantil de 1992, que surgiu após as "Diretas Já". Verifica-se, portanto, que há uma nova prática de organização, interlocução e articulação para a concretização da democracia e liberdade de expressão.

Os referidos movimentos urbanos e nacionais deixaram a militância como herança para a nova geração, abrindo-lhe a possibilidade de participação "[...] com um controle social mais efetivo, menos cooptada e menos caudatária às redes de clientelismo.” (GOHN, 2013, p. 171). Caracterizando novas formas de organização social, articuladas pelos meios de comunicação e através de fóruns específicos, os movimentos sociais urbanos reconhecem no plano dos valores ou da moral que tais processos de mobilização giram em torno de projetos sociais mais amplos do que apenas a reivindicação sem objetivos, apenas para tumultuar o processo democrático.

Com as mudanças sociais e políticas ocorridas no século XXI emergem novos atores sociais, mobilizando-se em movimentos sociais urbanos como um mecanismo de inclusão social e oposição aos obstáculos à construção da democracia, segundo os princípios da cidadania. Registra-se, ainda, que a mobilização das massas no cenário político nacional é uma 
forma de pressão ou de manifestação para fazer o chamamento da sociedade, apresentando uma nova agenda, com novos atores, que querem ser partícipes do projeto de consolidação do espaço democrático.

É evidente que os movimentos sociais urbanos ganharam novos contornos nesse século e não podem ser pensados de forma isolada do contexto histórico e conjuntural do momento, no qual os novos interlocutores - não apenas aqueles representados pelas ONGs, associações, Terceiro Setor, mas cidadãos que mesmo não pertencendo a um ou outro - mobilizam-se e têm uma identidade modelada a partir das novas agendas de ideias e demandas (GOHN, 2013, p. 173), quais sejam, tornarem-se protagonistas da história em curso.

Há um processo de reformulação de novas políticas que vai alterando a identidade dos movimentos sociais populares, e não envolve apenas os cidadãos de uma determinada categoria socioeconômica e cultural. Assim, novas categorias passam a integrar e participar dos movimentos sociais, seja por meio de passeatas e fóruns, ou por debates nas redes sociais.

Partindo da constatação de que novos interlocutores estão surgindo e se mobilizando, Gohn (2011, p. 301) acredita que "A construção de uma nova concepção de sociedade civil é resultado das lutas sociais empreendidas por movimentos e organizações sociais nas décadas anteriores, que reivindicaram direitos e espaços de participação social."

Nesta perspectiva, alguns elementos são necessários para a participação de sujeitos que antes eram meros espectadores e agora se inserem nos movimentos sociais como protagonistas. Suas ações devem ser permeadas pela ética e solidariedade, pois conforme Gohn (2013, p. 173), elas precisam aprender a "[...] identificar projetos diferentes ou convergentes, gerados como respostas às pressões e demandas socioeconômicas que elas fazem."

De tudo isso se abstrai que "Este espaço é trabalhado segundo princípios da ética e da solidariedade, enquanto valores motores de suas ações, resgatando as relações pessoais, diretas e as estruturas comunitárias da sociedade [...]." (GOHN, 2011, p. 301). Ao mesmo tempo,

\footnotetext{
Resgatam-se regras de civilidade e de reciprocidade ao se reconhecer como detentores de diretos legítimos os novos interlocutores: grupos de favelados, de mulheres discriminadas, de crianças maltratadas, de ecologistas militantes, de sem-terra e/ou sem-teto, entre outros. [...] assiste-se, na sociedade brasileira, à recriação da esfera pública - que leva alguns analistas a falarem em reinvenção da república. (GOHN, 2011, p. 301).
}

Diante dessas considerações pode-se afirmar que com a emergência de novos atores há uma (des) mobilização dos movimentos populares urbanos, haja vista que as demandas deslocaram-se da agenda dos excluídos de uma determinada classe social e passaram a fazer 
parte da agenda de todos os brasileiros que vivem uma nova - mas não desconhecida democracia participativa.

O que se modifica com esses deslocamentos de pautas são as identidades múltiplas dos sujeitos e dos interlocutores que agem em redes, com demandas e problemas sociais diferentes dos grupos sociais que lutam para ter um mínimo existencial para uma sobrevivência com a dignidade. Por isso, se reconhece "[...] que nem todas as ações coletivas desenvolvem laços de pertencimento, assim como não desenvolvem a consciência de resistência ou o desejo de emancipação social." (GOHN, 2013, p. 169).

Faz-se necessário, portanto, a presença de novos atores para demonstrar que a articulação desses movimentos não se dá por contraposição ao Estado e à ideologia vigente, mas a favor de um Brasil menos corrupto, com políticas públicas voltadas ao cidadão hipossuficiente. Ademais, acredita-se na necessidade de redefinição do papel do Estado, "restaurando a esperança e a crença que vale a pena lutar por uma sociedade mais justa e igualitária" (GOHN, 2011, p. 342), pois o que se observa é que não mais atende às necessidades e demandas da população.

Em síntese, os novos atores sociais que emergiram na sociedade brasileira configuram novos espaços e formatos de participação e de relações sociais e, inevitavelmente vão se integrando por meio das redes sociais e comunidades e ocupando um espaço que antes não lhes interessava. A tendência é aumentar a participação em questões políticas e sociais, evidenciando que "[...] a capilarização do acesso às redes eletrônicas, incluindo os celulares e os dispositivos móveis [...]" (GUZZI, 2014, p. 240), está possibilitando que esses novos atores reconheçam que podem contribuir para o fortalecimento da democracia e da cidadania.

\section{Conclusão}

A pretensão deste artigo não foi esgotar o assunto, e sim analisar a importância dos movimentos sociais urbanos em relação aos atuais meios de comunicação para a consolidação da democracia e liberdade de expressão, cujas garantias são previstas constitucionalmente.

Os movimentos sociais, tanto urbanos quanto rurais, em suas diversas formas e objetivos, possuem uma finalidade em comum, qual seja, a manutenção da democracia e da liberdade de expressão.

Assim, é perceptível que os movimentos sociais existem há anos, e que até hoje são utilizados para que a democracia só "caminhe para frente”, pois é uma das formas de controlar 
e ajudar o governo a gerir o Brasil. Quando o povo não é ouvido por seus representantes políticos, ele sai às ruas para lutarem por seus direitos.

Observa-se, contudo, um ponto crítico: nem toda movimentação da sociedade é um movimento social reconhecido. Não basta, portanto, o intento de sair às ruas, de forma descontrolada, sem ao menos possuir um objetivo/finalidade em comum. Ademais, não se pode reconhecer o movimento se as pessoas saem de maneira desordenada para batalhar por direitos que sequer reconhecem como seus, apenas pela participação e popularidade. Movimentos dessa espécie possibilitam a infiltração de sujeitos com objetivos diversos daqueles por ventura defendidos, com a marginalização de condutas e o cometimento de crimes.

Quando se trata de movimentos criados em redes sociais é preciso saber do que se trata, e se realmente está de acordo com o que a sociedade necessita. Muitos movimentos são organizados com o fito de legalizar a participação de "baderneiros", incitando confusões e violência, sem aproveitar o momento para a consecução de roubos, furtos, depredação de patrimônios, etc.

O principal foco deste artigo foi demonstrar aos leitores que os movimentos sociais precisam estar presentes na sociedade a fim de consolidar a democracia, em especial porque exteriorizam o direito à liberdade de expressão.

Não se pode deixar de mencionar também, que a consolidação da democracia e a exteriorização da liberdade de expressão surgem com a emergência de novos atores sociais que fazem parte de várias classes sociais. As manifestações passaram a fazer parte da agenda de todos os brasileiros que vivem uma nova - mas não desconhecida - democracia participativa.

Em síntese, os novos atores sociais que emergiram na sociedade brasileira configuram novos espaços e formatos de participação e de relações sociais e, inevitavelmente, estes vão se integrando por meio das redes sociais e comunidades e ocupando um espaço que antes não lhes interessava. A tendência é aumentar a participação em questões políticas e sociais, evidenciando a necessidade da presença de novos atores para demonstrar que a articulação desses movimentos não se dá por contraposição ao Estado e à ideologia vigente, mas a favor de um Brasil menos corrupto, com políticas públicas voltadas não só ao cidadão hipossuficiente, mas a todos que lutam por um país melhor.

Acredita-se, portanto, na necessidade de redefinição do papel do Estado, ou seja, um Estado comprometido com a justiça social e o bem-estar de todos e não de apenas uma determinada classe social.

Barbarói, Santa Cruz do Sul, Edição Especial n.44, p.<87-105>, jul./dez. 2015 


\section{Referências}

ALVES, Teresa Costa. Média, movimentos sociais e democracia participativa: as mensagens políticas nos cartazes da manifestação de 15 de setembro de 2012. Estudos em Comunicação. Portugal: Centro de Estudos de Comunicação e Sociedade (CECS), Universidade do Minho, $\mathrm{n}^{\circ}$ 14, dez., 2013.

ARAÚJO, Ana Paula de. Textos jornalísticos. Disponível em: http://www.infoescola. com/redacao/textos-jornalisticos/. Acesso em: 13 mar. 2015.

GOHN, Maria da Glória. Movimentos sociais e redes de mobilizações civis no Brasil contemporâneo. 7. ed. Petrópolis, RJ: Vozes, 2013.

Teorias dos movimentos sociais. 9. ed. São Paulo: Loyola, 2011.

(Org.). Movimentos sociais no início do século XXI: antigos e novos atores sociais. 2. ed. Rio de Janeiro: Vozes, 2004.

GUZZI, Adriana de Araújo. Web e Participação: a democracia no século XXI. São Paulo: Senac, 2014.

LEVY, Pierre. Inteligência Coletiva. São Paulo, SP: Ed. Loyola, 2011.

MEIO \& MENSAGEM. Facebook tem 89 milhões de usuários no Brasil. Disponível em: http://www.meioemensagem.com.br/home/midia/noticias/2014/08/ 22/Facebook-tem-89milhoes-de-usuarios-no-Brasil.html\#ixzz3VARqpOxl. Acesso em: 22 mar. 2015.

NASCIMENTO, Valéria Ribas de; RODRIGUES, Marcio Schorn. A sociedade informacional em xeque: princípio da publicidade versus direito à intimidade e a Lei $n^{\circ} 12.527 / 11$. In: OLIVEIRA, Rafael de; BUDÓ, Marília de Nardin (Orgs.). Mídias da sociedade em rede (Orgs.) Ijuí, RS: Ed. Unijuí, 2014.

OLIVEIRA, Rafael Santos de; RODEGHERI, Letícia Bodanese. As potencialidades de participação popular na internet: análise do Portal da Câmara dos Deputados. Disponível em: http://www.publicadireito.com.br/artigos/?cod=67ff32d40fb51f1a. Acesso em: 10 mar. 2015.

PEREIRA, Marcus Abílio. Internet e mobilização política - os movimentos sociais na era digital. Disponível em: http://www.compolitica.org/home/wpcontent/uploads/2011/03/Marcus-Abilio.pdf. Acesso em: 10 mar. 2015.

RIBEIRO, Paulo Silvino. Movimentos Sociais: Breve definição. Brasil Escola. Disponível em: http://www.brasilescola.com/sociologia/movimentos-sociais-breve-definicao.htm. Acesso em: 20 mai. 2014. 


\section{Sobre as autoras:}

Luana Nascimento Perin é egressa do curso de Direito. Endereço eletrônico: luana.perin@unijui.edu.br

Eloísa Nair de Andrade Argerich é Docente da disciplina Direito Constitucional II, Departamento de Ciências Jurídicas e Sociais (DCJS) da Universidade Regional do Noroeste do Estado do Rio Grande do Sul (Unijuí). Endereço eletrônico: argerich@ @unijui.edu.br 